\title{
ANÁLISE DO POTENCIAL EÓLICO OFFSHORE DO CEARÁ EM PERÍODOS DE EL NIÑO E LA NIÑA
}

Danielle Kely Saraiva de Lima*1, Ruth P. S. Leão ${ }^{1}$, Antônio Carlos S. dos Santos², Francisca Dayane Carneiro Melo ${ }^{1}$, Camylla Maria Narciso de Melo Chaves ${ }^{1}$

\author{
${ }^{1}$ Universidade Federal do Ceará (UFC) \\ ${ }^{2}$ Universidade Estadual do Ceará (UECE) \\ *danielle.kely@dee.ufc.br
}

\section{RESUMO}

A Energia Eólica Offshore já é uma tecnologia amplamente desenvolvida na União Europeia com aproximadamente $5 \mathrm{GW}$ instalados até o final de 2012. No Brasil, são poucos os estudos neste segmento e a análise do potencial é essencial para indicar os possíveis locais de implantação de parques no mar.

A análise feita, utilizando períodos de El Niño e La Niña, mostrou que mesmo em períodos com presença de eventos extremos, a costa cearense apresenta valores de velocidade média do vento favoráveis á instalação de parques eólicos offshore.

\begin{abstract}
The Offshore Wind Energy is a technology already widely developed in the European Union with approximately 5GW installed by the end of 2012. In Brazil there are few studies in this segment and potential analysis is essential to indicate the possible locations where parks at sea.

The analysis using periods of El Niño and La Niña periods showed that even in the presence of extreme events Ceará coast shows values of mean wind speed will favor the installation of offshore wind farms.
\end{abstract}

\section{INTRODUÇÃO}

Apesar dos ventos no litoral do Nordeste brasileiro possuir boa intensidade e constância dos ventos alísios, o vento está sujeito à variabilidade e tem uma intrínseca relação com os fenômenos meteorológicos, sendo muito importante entender de que forma isso pode influenciar na geração eólica (OLIVEIRA e COSTA, 2011).

Um dos fenômenos que influenciam bastante no regime de vento e precipitações no Nordeste brasileiro são o El Niño e a La Niña. O objetivo deste trabalho é apresentar uma análise do potencial eólico offshore da costa cearense para estes períodos. 


\section{MATERIAIS E MÉTODOS}

O modelo de mesoescala utilizado é o RAMS 6.0 (Regional Atmospheric Model System) e foi inicializado a partir de dados de reanálise do NCEP.

Para este trabalho em específico, foram feitas simulações do mês de abril de 2008 (período chuvoso de La Niña); abril de 1998 (período chuvoso de El Niño); outubro de 2007 (período seco de La Niña) e outubro de 1997 (período seco de El Niño). Foram usadas três grades, sendo a terceira com $2 \mathrm{~km}$ de resolução.

\section{RESULTADOS E DISCUSSÃO}

Na Figura 1, os valores médios de velocidade encontrados para outubro de 1997 estão na faixa de $7 \mathrm{~m} / \mathrm{s}$ a $9 \mathrm{~m} / \mathrm{s}$ em quase todo o litoral, somente no extremo oeste aparecem valores entre $9 \mathrm{~m} / \mathrm{s}$ e $11 \mathrm{~m} / \mathrm{s}$. Na Figura 2, os valores médios observados de velocidade do vento em outubro de 2007 são de $11 \mathrm{~m} / \mathrm{s}$ a $13 \mathrm{~m} / \mathrm{s}$ em quase todo o litoral e somente no litoral leste os valores apresentados estão na faixa de $9 \mathrm{~m} / \mathrm{s}$ a $11 \mathrm{~m} / \mathrm{s}$.

Na Figura 3, os valores médios de velocidade do vento para abril de 1998 apresentam valores na faixa de $5 \mathrm{~m} / \mathrm{s}$ a $7 \mathrm{~m} / \mathrm{s}$. Na Figura 4, os valores médios de velocidade do vento para abril de 2008 apresentam valores na faixa de $5 \mathrm{~m} / \mathrm{s}$ a $7 \mathrm{~m} / \mathrm{s}$ no litoral oeste e $3 \mathrm{~m} / \mathrm{s}$ a $5 \mathrm{~m} / \mathrm{s}$ no litoral leste.

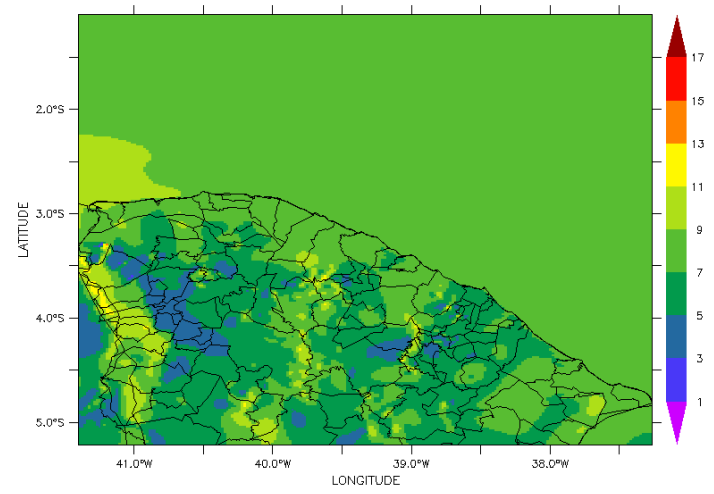

Figura 1: Velocidade média $(\mathrm{m} / \mathrm{s})$ em outubro de 1997 a 100m.

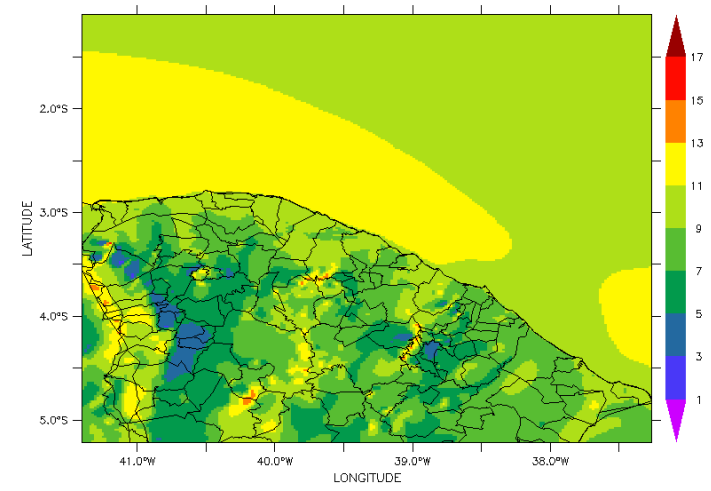

Figura 2: Velocidade média (m/s) em outubro de 2007 a 100m. 


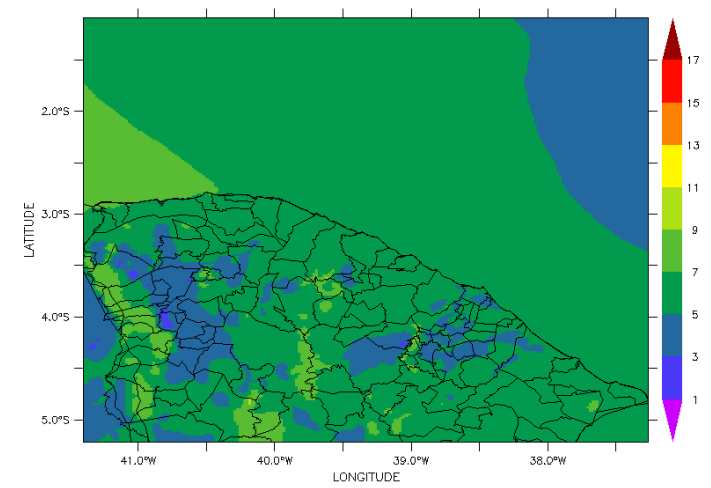

Figura 3: Velocidade média (m/s) em abril de 1998 a 100m.

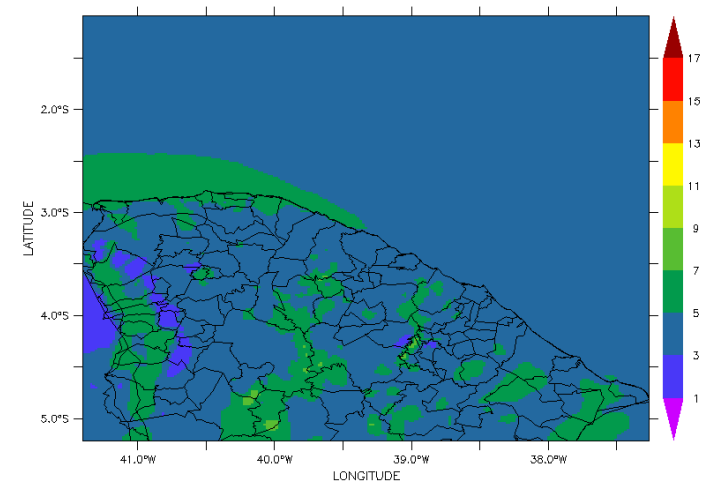

Figura 4: Velocidade média (m/s) em abril de 2008 a 100m.

\section{CONCLUSÕES}

Os resultados revelam que nas duas situações estudadas de ano com El Niño e com La Niña, no período seco, os valores de velocidade média do vento são satisfatórios, sendo capazes de gerar grande quantidade de energia. No período chuvoso, os valores são menores causando uma consequente diminuição da geração em ambos.

\section{AGRADECIMENTOS}

A CAPES e FUNCAP pelo apoio financeiro e ao Mestrado Acadêmico em Ciências Físicas Aplicadas pelo suporte técnico.

\section{REFERÊNCIAS}

OLIVEIRA, Juliana Lima; COSTA, Alexandre Araújo. Estudo de variabilidade do vento em escala sazonal sobre o nordeste brasileiro utilizando o RAMS: os casos de 19731974 e 1982-1983. Revista Brasileira de Meteorologia, v.26, n.1, 53 - 66, 2011. 